\title{
Modelling and simulation of a wind energy system
}

\author{
Cristian-Gabriel Alionte ${ }^{1}$ and Liviu-Marian Ungureanu ${ }^{2, *}$ \\ ${ }^{1}$ University Politehnica of Bucharest, Mechatronics and Precision Mechanics Department, RO- \\ 060042 Splaiul Independentei, No.313 room CH 402, Romania \\ ${ }^{2}$ University Politehnica of Bucharest, Theory of Mechanisms and Robots Department, RO-060042 \\ Splaiul Independentei, No.313 room JC111, Romania
}

\begin{abstract}
Nowadays, wind energy systems are the most efficient systems of all renewable energy production systems. Therefore, all sizes and types of this kind of systems are available, but there are few portable systems which can be temporarily mounted in certain isolated areas. We propose in this case study another solution as an alternative: an adaptable mechatronic system which can withstand even in very difficult and challenging weather conditions due to their active surfaces that have reconfigurable automatic structure.
\end{abstract}

\section{Introduction}

Wind energy systems have been known since ancient times [1], the sail boat is considered the earliest use of wind power (approx. 1000 B.C.) which has developed in sail-type windmills which was used to power the grain-grinding and water-pumping. The first vertical system was made in Persia about 500-900 A.D. but without documents it's not known the application type. Also, in 1219 A.D. another vertical-axis windmills have been documented by the Yehlu Chhu-Tshai a Chinese statesman. Another application of a wind power is the using of hundreds of sail-rotor windmills for water pumping of crops and livestock on the Crete island. In western Europe the first documented windmill is in 1270 A.D. and was a horizontal-axis configuration. In 1390, in Holland had been developed the tower mill design, which in the later design can be oriented into the wind manually, and in this way, the energy of the windmill and the power output was optimized, and the mill was protected from damage. In the beginning of the $19^{\text {th }}$ century the development of the wind energy turbines has decrease because of the using of the steam engines until the $20^{\text {th }}$ century when finding new energy sources, especially non-pollutant and regenerable, has become a main issue.

In principle, a wind energy generating system consists of the following components, see Fig. 1 where the most important part is the wind runner. Now, exist many shapes and dimensions, and can be with horizontally axis (HAWT) or vertically axis (VAWT). We focused on the VAWT because the weight did not introduce any force and can be achieved a perfect balance of the mechanical system.

* Corresponding author: ungureanu.liviu.marian@gmail.ro 


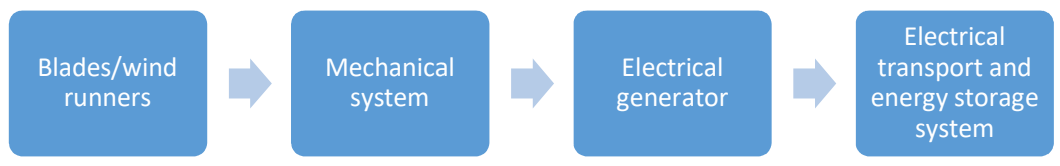

Fig. 1. Components of the wind energy generating system.

Typical wind runners of vertical axis used are Darrieus, helical, drag cup, Savonius, and $\mathrm{H}$ type, presented in fig. 2.

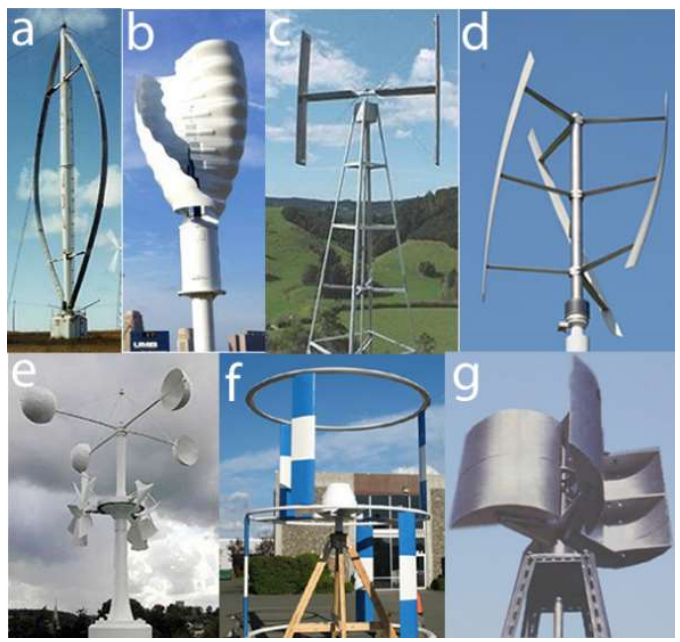

Fig. 2. Different types of vertical axis wind runners : a) Darieus [2]; b) Helix geometry[3]; c) H geometry [4]; d) Turby [5]; e) Drag cup [2]; f) Hybrid vertical wind turbine [2]; g) Savoniuos [6].

The design of the wind runner is important because influence the efficiency of the allwind energy system and the protection of the system in case of powerful wind or storms. This is why we suggest making a vertical wind energy system with adaptable position of runners.

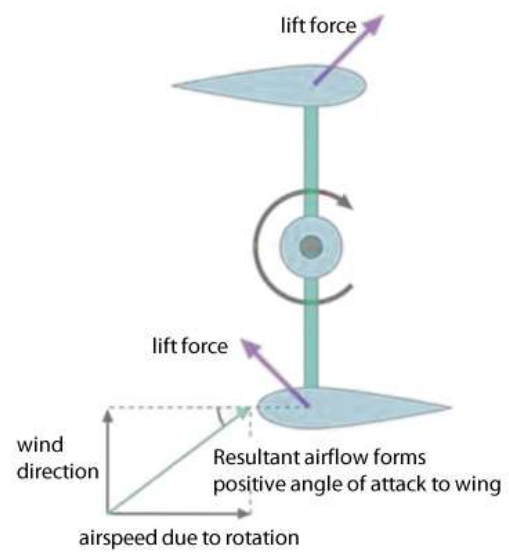

Fig. 3. Working principle of vertical axis wind runner [2].

The mechanical power generated by the vertical axis wind runner is:

$$
\mathrm{P}=\omega \cdot \mathrm{T}
$$




\section{Where}

$\omega$ - represents the angular velocity of the axis

$\mathrm{T}$ - represent the torque

Usually, the wind energy system is more efficient if the power coefficient $\left(\mathrm{C}_{\mathrm{P}}\right)$ is higher. It is defined as the ratio of the power converted from the rotor power to the wind power flowing, it is a concept of aerodynamic energy conversion efficiency [8] and is also influenced by the power transmission efficiency $(\eta)$ of the mechanical system used for transforming and transmitting the mechanical power to the electrical generator. This coefficient has a maximum value at a specific tip speed ratio $(\lambda)$ and for example, Darrieus runner has a maximum power coefficient of about 0.4 at a tip speed ratio of 5 and all turbines has an optimum tip speed ratio with maximum power and is related it the speed of the wind (V). The tip speed ratio is the ratio of the wind runner tip speed and the wind speed at which the wind runner tip moves with rotation, is related with power coefficient, and can be described as:

$$
\lambda=\mathrm{R} \cdot \omega \cdot \mathrm{V}^{-1}
$$

The power output $(\mathrm{P})$ is:

$$
\mathrm{P}=\rho \cdot \mathrm{R} \cdot \mathrm{H} \cdot \mathrm{V}^{3} \cdot \eta \cdot \mathrm{C}_{\mathrm{p}}
$$

Where

$\rho$ - is the density of air;

$\mathrm{R}$ - is the radius of the runner;

$\mathrm{H}$ - is the height of the wind runner.

The radius $(\mathrm{R})$ multiplied by the height $(\mathrm{H})$ represents the wind-swept area $\left(\mathrm{A}_{\omega}\right)$. The bigger $A_{\omega}$ the bigger $\mathrm{P}$ become. If the $\mathrm{R}$ is longer, the generated torque is higher, but the solidity $(\sigma)$ is lower and the generated torque is lower. If the $H$ is longer than the rotational speed of the rotor should be increased to obtain the same power output. The solidity is defined as the ratio of total projected area of the rotor wind runner $(\mathrm{NC}$, which is the number of wind runner multiplied by projected area) to the rotational area of the wind runner rotor [7].

So, by modifying the angle of the vertical runner with the according with the wind direction the angular velocity is increasing so the output power is increasing. In this way the system is efficient even at low wind speed, and this is why we chose to analyze such system by modeling and simulation considering a prototype design with four wind runners presented in Fig. 4 which is modifying the angle according with the wind direction.

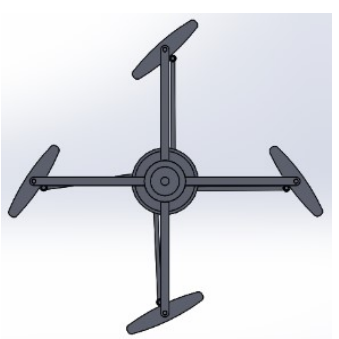

a)

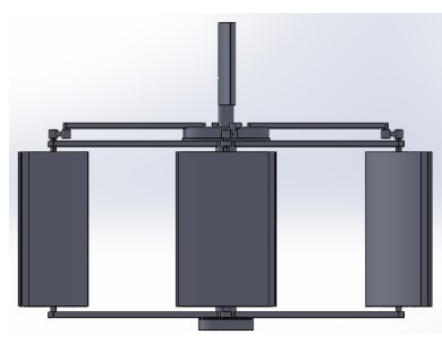

b)

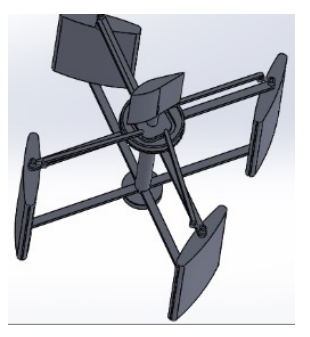

c)

Fig. 4. The prototype design of wind runner with four wind runners: a) Front view; b) Top view; c) Isometric view. 


\section{Method for calculation for the wind runners orientation system used in a vertical wind turbine}

For calculation $[9,10]$ for the wind runners orientation system, we started to analyses one wind runner (as can be seen in Fig. 5) because our design is axial symmetric. There for the method can be applied starting for two or four wind runners as presented in our case or more.

The vertical wind turbine system consists of a quadrilateral mechanism (ABCD) and in the joint $A$ is fixed the wind runner at the middle of its width. The element 3 (CE) has a ball bearing for the friction reduction, which it is fastened in the joint $\mathrm{E}$, and it is rotated by the roller which has a role of follower for the cam 4 having a translation movement. For the determination of the kinematic parameters of the quadrilateral mechanism, we can use equations 1 and 2 .

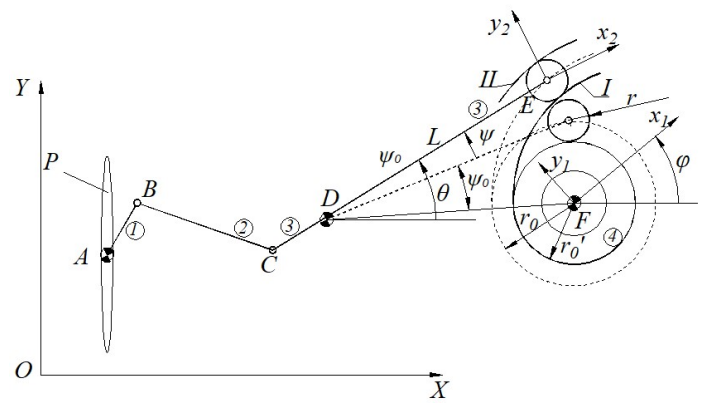

Fig. 5. Structure diagram for analyses.

The position of the mechanism is given by the value of the angle of the crank 1 (starting from $30^{\circ}$ ) and corresponds to the minimum angle made by the vector DC with Ox axis, considering the positive direction (elements 1 and 2 are in the extension). Determining this position [9] is given by the equation:

where

$$
\varphi=\arccos \left(\frac{\mathrm{XD}}{\mathrm{AD}}\right)+\arccos \left(\frac{\mathrm{AD}^{2}+(\mathrm{AB}+\mathrm{BC})^{2}-\mathrm{CD}^{2}}{2 \mathrm{AD}(\mathrm{AB}+\mathrm{BC})}\right)
$$

$$
\mathrm{AD}=\sqrt{\mathrm{XD}^{2}+\mathrm{YD}^{2}}
$$

For the synthesis of the rotating cam mechanism, which acts as a cylindrical active rotating surface, we can use the circle family envelope equations, which is moving with the center on the theoretical profile, are

$$
\begin{aligned}
& \left(x-x_{1 i}\right)^{2}+\left(y-y_{1 i}\right)^{2}-r^{2}=0 \\
& \left(x-x_{1 i}\right) \frac{d x_{1 i}}{d \varphi_{i}}+\left(y-y_{1 i}\right) \frac{d y_{1 i}}{d \varphi_{i}}=0
\end{aligned}
$$

where:

$\mathrm{i}=\mathrm{step}$

$$
\begin{aligned}
& \mathrm{x}_{1 \mathrm{i}}=(\mathrm{XE}-\mathrm{XF}) \cos \varphi_{i}+(\mathrm{YE}-\mathrm{YF}) \sin \varphi_{i}+\mathrm{L} \cos \left(\theta_{i}-\varphi_{i}\right) \\
& \mathrm{y}_{1 \mathrm{i}}=-(\mathrm{XE}-\mathrm{XF}) \sin \varphi_{i}+(\mathrm{YE}-\mathrm{YF}) \cos \varphi_{i}+\mathrm{L} \sin \left(\theta-\varphi_{i}\right)
\end{aligned}
$$




$$
\begin{gathered}
\frac{\mathrm{dx}_{1_{\mathrm{i}}}}{\mathrm{d} \varphi_{i}}=-(\mathrm{XE}-\mathrm{XF}) \cos \varphi_{i}+(\mathrm{YE}-\mathrm{YF}) \sin \varphi_{i}+\mathrm{L} \sin \left(\theta_{i}-\varphi_{i}\right) \frac{\mathrm{d} \theta}{\mathrm{d} \varphi_{i}} \\
\frac{\mathrm{dy}_{1_{\mathrm{i}}}}{\mathrm{d} \varphi_{i}}=-(\mathrm{XE}-\mathrm{XF}) \cos \varphi_{i}-(\mathrm{YE}-\mathrm{YF}) \sin \varphi_{i}-\mathrm{L} \cos \left(\theta_{i}-\varphi_{i}\right) \frac{\mathrm{d} \theta_{i}}{\mathrm{~d} \varphi_{i}}
\end{gathered}
$$

By making the replacements in the above relationships, we obtain:

- the profile $I$ :

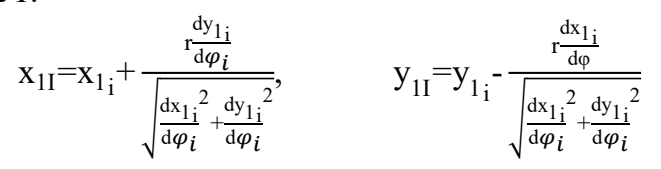

- the profile $I I$ :

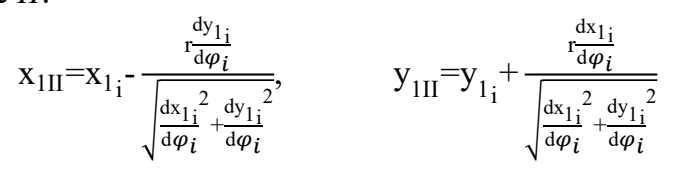

\section{Results and conclusions}

The joint $\mathrm{C}$ of the mechanism is fixed to the frame of the vertical wind runner. It can be seen in Fig. 5 that on the cam 4 (which has the joint F) is fastened a system, which establishes the wind direction, and which will move the cam 4 on this direction. The rotation movement of the $\mathrm{AB}$ element is limited on $\varphi=100^{\circ} \mathrm{deg}$. Starting from the above relationships, a calculation program developed in SciLAB has as input date the angle $\varphi$ in steps of $10^{\circ}$ starting from $30^{\circ}$ until $130^{\circ}$. In fig. 6 we can see some results from the program.

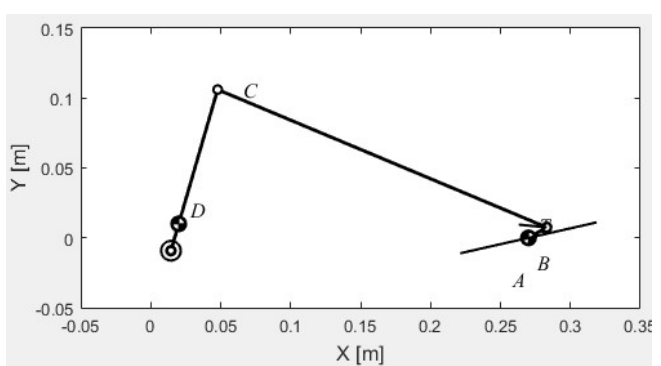

a)

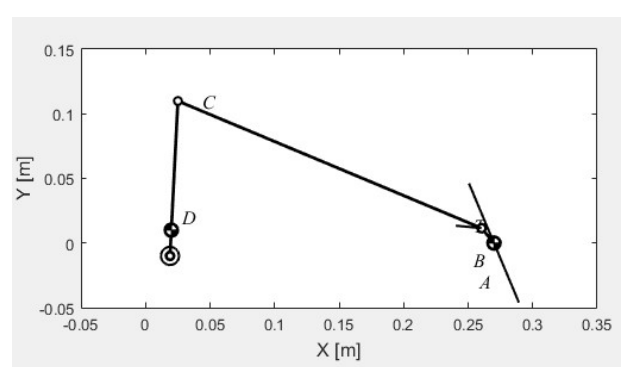

b)

Fig. 6. Graphical representation of the movement of the system at given angles: a) $\varphi=30^{\circ}$; b) $\varphi$ $=130^{\circ}$.

Numerical values obtained $\varphi$ are given in radian and are presented in Table 2.

Table 1. Numerical values obtained using the calculation method.

\begin{tabular}{|c|c|c|c|c|c|c|}
\hline $\begin{array}{c}\varphi \\
{[\mathrm{rad}]}\end{array}$ & $\begin{array}{c}\psi \\
{[\mathrm{rad}]}\end{array}$ & $\begin{array}{c}\theta \\
{[\mathrm{rad}]}\end{array}$ & $\begin{array}{c}\dot{\psi} \\
{[\mathrm{rad} / \mathrm{s}]}\end{array}$ & $\begin{array}{c}\dot{\theta} \\
{[\mathrm{rad} / \mathrm{s}]}\end{array}$ & $\begin{array}{c}\ddot{\Psi} \\
{\left[\mathrm{rad} / \mathrm{s}^{2}\right]}\end{array}$ & $\begin{array}{c}\ddot{\theta} \\
{\left[\mathrm{rad} / \mathrm{s}^{2}\right]}\end{array}$ \\
\hline 0.5230 & 2.7447 & 1.2889 & 0.4105 & 1.2012 & -3.7176 & 8.8836 \\
\hline 0.6975 & 2.7513 & 1.3112 & 0.3416 & 1.3398 & -4.1558 & 6.9619 \\
\hline 0.8721 & 2.7566 & 1.3355 & 0.2659 & 1.4429 & -4.5063 & 4.8136 \\
\hline 1.0466 & 2.7606 & 1.3613 & 0.1848 & 1.5068 & -4.7791 & 2.4771 \\
\hline 1.2211 & 2.7631 & 1.3879 & 0.0995 & 1.5285 & -4.9815 & -0.0043 \\
\hline 1.3957 & 2.7640 & 1.4144 & 0.0113 & 1.5061 & -5.1165 & -2.5815 \\
\hline 1.5702 & 2.7634 & 1.4402 & -0.0787 & 1.4382 & -5.1810 & -5.1972 \\
\hline
\end{tabular}




\begin{tabular}{|l|l|l|l|l|l|l|}
\hline 1.7447 & 2.7613 & 1.4643 & -0.1691 & 1.3248 & -5.1646 & -7.7829 \\
\hline 1.9193 & 2.7575 & 1.4862 & -0.2584 & 1.1672 & -5.0493 & -10.2559 \\
\hline 2.0938 & 2.7523 & 1.5048 & -0.3446 & 0.9680 & -4.8109 & -12.5177 \\
\hline 2.2683 & 2.7455 & 1.5197 & -0.4254 & 0.7321 & -4.4212 & -14.4562 \\
\hline
\end{tabular}

A wind runner according with the wind speed rotates the cam and the quadrilateral mechanism (ABCD) makes a complete rotation motion. Using the aforementioned calculation formulas in the same software, we verified the functioning of the vertical axis wind runner. In the fig. 7 we present the system in four distinct positions at $0^{\circ}, 90^{\circ}, 180^{\circ}, 270^{\circ}$.

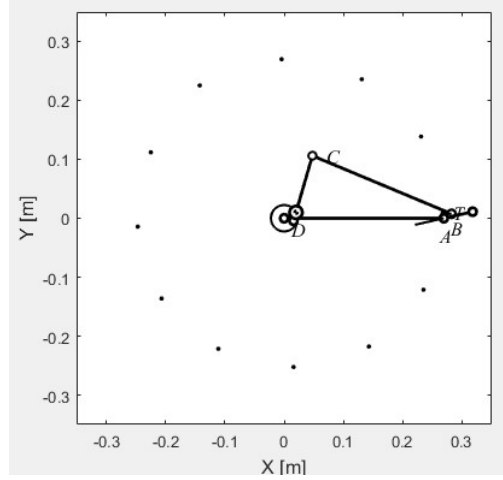

a)

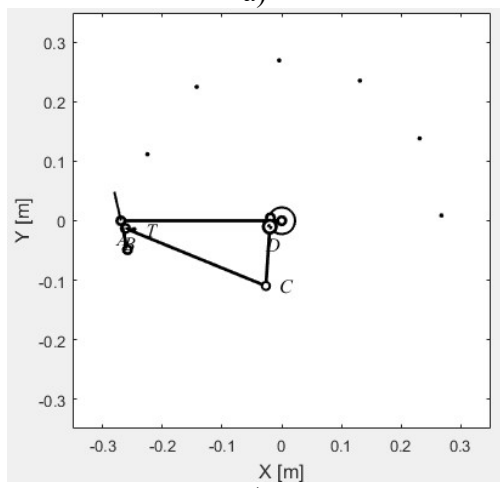

c)

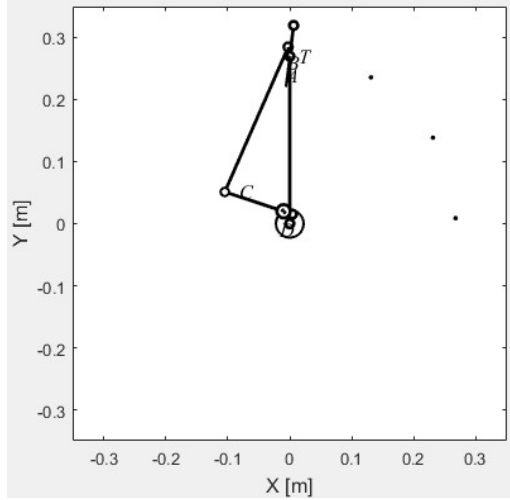

b)

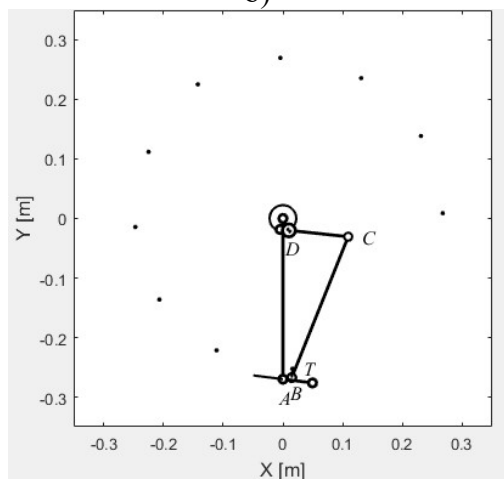

d)

Fig. 7. Graphical representation of the movement of the system at given angles: a) $0^{0}$; b) $90^{\circ}$; c) $180^{\circ}$; d) $270^{\circ}$.

The calculated numerical values for the quadrilateral mechanism are presented in table 2 when element 4 cam is on a fixed position by the wind energy.

Table 2. Numerical values for the quadrilateral mechanism obtained using the calculation method.

\begin{tabular}{|c|c|c|c|c|c|l|}
\hline $\begin{array}{c}\varphi \\
{[\mathrm{rad}]}\end{array}$ & $\begin{array}{c}\psi \\
{[\mathrm{rad}]}\end{array}$ & $\begin{array}{c}\theta \\
{[\mathrm{rad}]}\end{array}$ & $\begin{array}{c}\dot{\psi} \\
{[\mathrm{rad} / \mathrm{s}]}\end{array}$ & $\begin{array}{c}\dot{\theta} \\
{[\mathrm{rad} / \mathrm{s}]}\end{array}$ & $\begin{array}{c}\ddot{\psi} \\
{\left[\mathrm{rad} / \mathrm{s}^{2}\right]}\end{array}$ & $\begin{array}{c}\ddot{\theta} \\
{\left[\mathrm{rad} / \mathrm{s}^{2}\right]}\end{array}$ \\
\hline 0.0000 & 2.7448 & 1.2890 & 9.6718 & 9.0386 & -2.3803 & 5.6816 \\
\hline 0.5236 & 3.2520 & 1.7768 & 9.5834 & 9.3316 & -1.6277 & 7.6240 \\
\hline 1.0472 & 3.7756 & 2.3004 & 9.5065 & 9.2083 & -2.2839 & 10.6977 \\
\hline 1.5708 & 4.2992 & 2.8239 & 9.5065 & 9.2083 & -2.2294 & 10.7852 \\
\hline 2.0944 & 4.8457 & 3.4056 & 9.6765 & 8.7299 & -3.6974 & 6.3863 \\
\hline 2.6180 & 5.3776 & 4.0937 & 10.2033 & 8.8150 & -4.6204 & -7.9994 \\
\hline 3.1416 & 5.8938 & 4.6465 & 10.3269 & 9.0834 & -4.3555 & -11.1466 \\
\hline
\end{tabular}




\begin{tabular}{|l|l|l|l|l|l|l|}
\hline 3.6652 & 6.4174 & 5.1701 & 10.3269 & 9.0834 & -4.3555 & -11.1466 \\
\hline 4.1888 & 6.9410 & 5.6937 & 10.3269 & 9.0834 & -4.3555 & -11.1466 \\
\hline 4.7124 & 7.4737 & 6.1768 & 10.1605 & 8.7450 & -4.6554 & -6.8581 \\
\hline 5.2360 & 7.9990 & 6.6240 & 9.9061 & 8.5515 & -4.4639 & 0.1447 \\
\hline 5.7596 & 8.5162 & 7.0952 & 9.7483 & 8.6324 & -4.0200 & 4.4663 \\
\hline 6.2832 & 9.0279 & 7.5722 & 9.6112 & 8.8612 & -3.2971 & 8.0979 \\
\hline
\end{tabular}

The results presented in table 1 and table 2, proves that the wind energy system does not have singularities and the combination between two mechanisms cam with roller follower and quadrilateral mechanism, which has the positions in Fig. 7, are representing a feasible solution. In conclusion, our proposed wind energy system can modify the angle of the runners according with the wind direction if we use a passive mechanism presented in Fig.4 or with the wind direction and speed when we use an active mechatronic which comprise a speed sensor for sensing and a dc motor for actuation. However, the disadvantage is the possible contact wear in the area where the follower and cam come in contact. At next step we will focus our work on integration of this type of wind runner in different sound absorption or safety autonomous systems.

\section{References}

1. https://www.vertogen.eu/wind-turbine-history/

2. M. Ragheb, Vertical axis wind turbines (2015)

3. https://www.treehugger.com

4. https://www.hurricanewindpower.com

5. https://www.renugen.co.uk

6. https://vertogen.eu

7. H. Dowon, G. H. Young, J. C. Nak, H. N. Sang, H. C. Kyoung and C. K. Kyung, Design, Fabrication, and Performance Test of a 100-W Helical-Blade VerticalAxisWind Turbine at Low Tip-Speed Ratio, Energies, 11, 1517 (2018)

8. F. Niculescu, A. Săvescu, and C. Borzea, Analogue flow control of a network of centrifugal air compressors. At International Conference on Applied and Theoretical Electricity, Craiova, Romania (2018).

9. V. Moise, I. Simionescu, M. Ene, A. Rotaru, Analysis of plane mechanisms with hinged bars. Applications in MATLAB, Ed. Printech (2015)

10. V. Moise, I. Simionescu, M. Ene, Optima Synthesis of mechanisms with plane cam. Applications in MATLAB, Ed. Printech (2018) 